\title{
Radial Immunodiffusion
}

National Cancer Institute

\section{Source}

National Cancer Institute. Radial Immunodiffusion. NCI Thesaurus. Code C119296.

A quantitative technique used to detect and estimate the concentration of an antigen by measuring the diameter of the ring of precipitation (precipitin ring), which is formed as a result of the interaction of the antigen and an antibody at optimal concentration. 